\title{
Cartas al Editor
}

Se invita a los lectores a enviar cartas al Editor, con comentarios, preguntas o críticas sobre artículos que hayan sido publicados en la Revista y a las que los autores aludidos puedan responder. También serán bienvenidos los comentarios sobre problemas de actualidad biomédica, clínica, de salud pública, de ética y de educación médica. Podrá aceptarse la comunicación preliminar de datos parciales de una investigación en marcha, que no haya sido publicada ni sometida a publicación en otra revista. La extensión máxima aceptable es de 1.000 palabras, con un máximo de 6 referencias bibliográficas (incluyendo el artículo que la motivó) y 1 Tabla o Figura. Se recomienda adjuntar una copia idéntica para PC, en diskette de 3,5", un espaciado a 1,5 líneas, tamaño de letra 12 pt y justificada a la izquierda. Las cartas que se acepten podrán ser acortadas y modificadas formalmente, por los Editores.

\section{Declaración universal de bioética y derechos humanos de U N ESCO}

\section{UNESCO universal statement on bioethics and human rights}

$\mathrm{S}^{\mathrm{r}}$ $r$ Editor: En comunicaciones a esta Revista he nformado sobre mis actividades como miembro del Comité de Bioética de UNESCO durante las últimas décadas ${ }^{1-3}$. En esta oportunidad informo sobre mi participación, como consejero de la Delegación de Chile en UNESCO en las reuniones del Comité Intergubernamental en los meses de junio de 2004 y 2005, que elaboró el texto final de la nueva Declaración Universal sobre Bioética y Derechos Humanos, que se promulgará oficialmente en noviembre de 2005.

Esta Declaración ha sido adoptada por dicho Comité, formado por delegados de 85 naciones, que revisaron y corrigieron el anteproyecto durante la semana del 20 al 24 de junio de 2005 en la sede de la UNESCO en París. La adopción del articulado se hizo por consenso, ya que la Declaración no es vinculante para los estados miembros. Resumo en esta carta el contenido de los elementos más significativos de dicho Documento.

\section{Pré́mbulo}

Los rápidos adelantos de la ciencia y de la tecnología, que afectan cada vez más a nuestra concepción de la vida, han traído consigo una fuerte demanda para que se dé una respuesta universal a los problemas éticos que plantean estos adelantos.

La Constitución de UNESCO, aprobada en 1945, vela por el respeto universal a la justicia, a la ley, a los derechos humanos y a las libertades fundamentales.

Durante la última década la UNESCO ha elaborado dos Declaraciones sobre Bioética del Genoma Humano ${ }^{1,3}$. En este año 2005 ha adopta- 
do una nueva Declaración Universal sobre Bioética y Derechos Humanos, que define un amplio concepto de bioética.

La UNESCO define bioética como el estudio sistemático, pluralista e interdisciplinario para la resolución de los problemas éticos planteados por la medicina, las ciencias de la vida y las ciencias sociales cuando se aplican a los seres humanos, y a su relación con la biósfera, comprendidas las cuestiones relativas a la disponibilidad y accesibilidad de los adelantos científicos y tecnológicos y sus aplicaciones.

\section{OBjetivos}

La finalidad de esta Declaración es suscitar y estimular nuevos debates sobre problemas éticos y de su resolución en los estados miembros, con el fin de ampliar el alcance de este documento. Este es un instrumento universal de sensibilización, difusión de la información, educación y promoción del debate público. Para estos efectos ofrece un marco universal de principios que deben ser respetados por la dignidad de los seres humanos; reconoce los beneficios derivados de los adelantos científicos, promoviendo un acceso equitativo a ellos. Reconoce además el respeto a la biodiversidad y protege los intereses de las generaciones actuales y venideras.

\section{PRINCIPIOS}

La Declaración enumera y define brevemente los principios bioéticos que han sido aceptados universalmente en anteriores Declaraciones de UNES$\mathrm{CO}$ y de otras organizaciones y sociedades científicas internacionales.

Los principios éticos que se enuncian deben ser respetados por los responsables políticos nacionales e internacionales, por los prestadores de salud y por los grupos, organismos profesionales y asociaciones de científicos, porque representan distintas justificaciones racionales a las acciones humanas. Estos principios se pueden clasificar en tres niveles de relaciones:

1. Principios relacionados directamente con la dignidad humana: derechos humanos, libertades fundamentales, autonomía, consentimiento y confidencialidad.
2. Relaciones entre los seres humanos: solidaridad, cooperación, responsabilidad social, equidad, beneficencia, justicia y diversidad cultural.

3. Relaciones entre seres humanos y otras formas de vida y con la biósfera.

Estos principios se pueden resumir:

- La dignidad humana y los derechos humanos exigen que los intereses y el bienestar de la persona humana prevalezcan sobre el interés exclusivo de la ciencia y de la sociedad.

- La igualdad fundamental de los seres humanos exige que sean tratados con justicia y equidad.

- En las decisiones prácticas que se adopten, la persona interesada debe ser protegida de efectos nocivos, de discriminación, de estigmatización y con respeto a la diversidad cultural.

- En las investigaciones científicas deben respetarse la autonomía, la responsabilidad individual con el consentimiento previo, libre, informado y expreso de la persona interesada.

- El respeto a la vida privada y a la confidencialidad está asociada en forma irrestricta a una persona identificable.

- El progreso de la ciencia y de la tecnología deberá estar asociado a una responsabilidad social, al bien común de la humanidad, dentro de un contexto de solidaridad y cooperación internacional con poblaciones vulnerables. Los beneficios resultantes de las investigaciones deberán ser compartidos por todos los seres humanos.

- Finalmente, se reafirma la responsabilidad de que los seres humanos deben proteger el medio ambiente, la biodiversidad y la biósfera.

\section{IMPLEMENTACIÓN}

La Declaración enumera las normas sobre cómo estos principios deben ser aplicados con profesionalismo, honestidad, integridad, transparencia y considerando los conflictos de intereses. Deben ser promovidos los debates públicos pluralistas que respeten todas las opiniones. Los Comités de Ética deben ser independientes, autónomos, multidisciplinarios y pluralistas.

En los aspectos prácticos se deben evaluar y prevenir los riesgos de las aplicaciones científicas y tecnológicas en las experimentaciones en seres 
vivos. Se deben regular en forma equitativa las prácticas comerciales y económicas transnacionales y permitir la libre circulación de las actividades científicas. Los beneficios resultantes de las investigaciones científicas deben ser compartidos con la sociedad en su conjunto.

Los estados miembros de UNESCO deberán adoptar las disposiciones adecuadas para que los principios enunciados en la presente Declaración puedan ser aplicados libremente en sus poblaciones.

\section{CONCLUSIÓN}

A pesar de la amplitud del consenso alcanzado, esta Declaración dejó muchos problemas éticos marginados del texto final, debido a la imposibilidad de alcanzar unanimidad en el debate. Así pues, el primer principio ético relativo al

\section{REFERENCIAS}

1. UNESCO, Declaración Universal del Genoma Humanos y los Derechos Humanos. Rev Méd Chile 1997; 125: 1485-9.

2. Cruz-Coke R. Normas bioéticas de UNESCO para evitar prácticas eugenésicas en investiga- «respeto a la vida» no pudo ser integrado en el artículo dedicado a la dignidad humana y derechos humanos. Tampoco logró consenso introducir los «derechos reproductivos de la mujer» en el artículo sobre las responsabilidades sociales y sanitarias. Sin embargo, a pesar de estas omisiones, estimo que esta Declaración Universal de la UNESCO es el documento más completo, más fundamentado y de más amplia visión de la bioética y del humanismo que haya conocido y será un referente básico para una mejor comprensión y difusión de la defensa de los derechos humanos en el mundo.

\section{Dr. Ricardo Cruz-Coke M. Consejero \\ Delegación permanente de Chile ante UNESCO, 2003-2005}

ciones biomédicas. Rev Méd Chile 2000; 128; 679-82.

3. Cruz-Coke R. Principios bioéticos sobre datos genéticos humanos. Rev Derecho y Genoma 2003; 19; 31-40. 